\title{
ANÁLISE DO SALDO DE FLUXO SUBTERRÂNEO NA CARACTERIZAÇÃO HIDROLÓGICA DAS LAGOAS DO SISTEMA LACUSTRE BONFIM, RN - BRASIL
}

\section{Roberto Pereira}

Professor do Centro Federal de Educação Tecnológica do Rio Grande do Norte - CEFETRN; Doutor em Geologia de Engenharia - rpereira-roma@cefetrn.br

Recebido em agosto/2004 e Aceito em dezembro/2004

\section{RESUMO}

O trabalho compreende o desenvolvimento de um balanço hídrico para avaliar as contribuições das águas subterrâneas nas lagoas do sistema lacustre Bonfim-RN. O modelo teve como base a determinação mensal do saldo de fluxo do balanço no período de janeiro a dezembro de 1999, correspondente à diferença entre as entradas e saídas de águas subterrâneas. O estudo mostrou existir uma relação deste saldo com a classificação hidroquímica das lagoas. O saldo de fluxo apontou evidências de ser um bom indicador de pequeno escoamento superficial para a lagoa do Bonfim, o qual normalmente é desconsiderado. Por outro lado, quando não se verifica escoamento superficial, como é o caso das dunas, igualmente revela ser uma técnica de análise da recarga e do efeito de retardo da infiltração eficaz. Por fim, o saldo de fluxo também mostrou ser uma ferramenta importante no controle da disponibilidade hídrica das lagoas.

Palavras-chave: Lago, balanço hídrico, hidroquímica.

\section{ANALYSIS OF GROUNDWATER EXCHANGE FOR HIDROLOGICAL CARACTERIZATION IN LAKES FROM LAKE SYSTEM BONFIM, RN - BRAZIL}

\begin{abstract}
The present study comprises the development of a computational model of monthly hydrologic budget to assess groundwater flow exchange with Bonfim lacustrial system (RN - Brazil) and its hydrochemistry characteristics, water resources and aspects related to overland flow. The model is based on the residual flows or residual term of the water budget (the difference between ground-water inflow and leakage as the sole unknown term) to provide the basis for analysis of ground-water exchange with the lakes, during the period of research (January/1999 till December /1999). This report concluded that there is an relationship between ground-water inflow minus outflow and composition of the lakes, but contribution from overland flow can affect this response. In addition, using this water balance approach it was possible to show evidence of the effects of overland flow, underground recharge, environment impact over lake exploitation and discuss the infiltration lag.
\end{abstract}

Key - words: Lake, water balance, hidrochemistry. 


\section{ANÁLISE DO SALDO DE FLUXO SUBTERRÂNEO NA CARACTERIZAÇÃO HIDROLÓGICA DAS LAGOAS DO SISTEMA LACUSTRE BONFIM, RN - BRASIL}

\section{INTRODUÇÃO}

O sistema lacustre Bonfim tem sido alvo de muitos estudos recentemente, tendo em vista a utilização da água da lagoa do Bonfim para o atendimento do sistema adutor Agreste Trairi Potengi ou adutora Monsenhor Expedito Bonfim, o qual entrou em funcionamento em 01/08/98. A adutora Monsenhor Expedito, com $315 \mathrm{Km}$ de extensão, abastece 20 municípios das regiões Trairi e Potengi do estado do Rio Grande do Norte. Este sistema adutor encontra-se em funcionamento, com uma vazão de cerca de $240 \mathrm{~L} / \mathrm{s}$. No final do plano, no horizonte de projeto, ano 2016, a vazão deverá ser elevada para 452 $\mathrm{L} / \mathrm{s}$ beneficiando uma população de 222.336 habitantes. Inicialmente a adutora explotou somente da lagoa do Bonfim, conforme projeto inicial. Todavia, a partir de junho de 2000, por razões ambientais, passou a funcionar como um sistema misto não previsto (lagoas 87,6 L/s e poços - $97 \mathrm{~L} / \mathrm{s}$ ) e, atualmente, explota cerca de 120,24 L/s diretamente da lagoa do Bonfim e 121,46 L/s de poços telados em um aqüífero semiconfinado, conforme adiante, estes situados no lado oeste desta lagoa.

O sistema lacustre Bonfim, é formado por seis lagoas (Tabela 1): Bonfim (maior reservatório da região litorânea Oriental do estado do Rio Grande do Norte), Redonda, Urubu, Boa Água, Ferreira Grande e Carcará, todas conectadas pelo aqüífero livre, o qual é composto por rochas terciárias areno-argilosas da Formação Barreiras (PEREIRA et al., 1996). Esta aflora a oeste deste sistema associada com solos tipo latossólicos, entretanto da lagoa do Bonfim para leste verifica-se uma cobertura arenosa eólica, do Quaternário. No geral, evidenciam ausência de drenagem, indicando elevada taxa de infiltração e pouca influência dos fluxos superficiais para as lagoas. Esta região possui as seguintes características hidrometeorológicas: clima tropical úmido (As' na escala Köpper), pluviometria média igual a $1.273 \mathrm{~mm}$ (SUDENE, 1990), com máximos valores ocorrendo principalmente nos meses de março a julho. As precipitações no ano de 1999 estiveram abaixo da média, em torno de 845,8 mm.

A potenciometria do aqüífero livre (Figura 1) mostra claramente que o domínio oeste representa a principal área de recarga da lagoa do Bonfim $\left(18,895.10^{6} \mathrm{~m}^{2}\right)$. Neste mapa, os fluxos provenientes de oeste alimentam a lagoa do Bonfim, sendo que as perdas subterrâneas ocorrem para este mesmo aqüífero em direção ao rio Pium e à lagoa Boa Água, assim como para o riacho Timbó. Segundo Pereira (2001), perdas subterrâneas também podem ocorrer da lagoa do Bonfim para o aqüífero semi-confinado (Figura 1), o qual ocorre no setor oeste dessa lagoa, buscando o sentido do rio Trairi. A área de recarga deste aqüífero situa-se também no setor oeste e uma outra parcela dos fluxos neste compartimento buscam a zona de descarga do rio Pium. Este aqüífero inferior, com drenança descendente, foi identificado pela primeira vez por Melo \& Feitosa (1998), fugindo do escopo deste trabalho.

O presente estudo compreende o desenvolvimento de um modelo computacional de balanço hídrico a ser aplicado em algumas lagoas do sistema lacustre Bonfim, localizado a sul de Natal, no estado do Rio Grande do Norte (Figura 1), para analisar as entradas e saídas de águas subterrâneas e as relações existentes entre as suas características 
hidroquímicas, disponibilidades hídricas subterrâneas do período, bem como aspectos relacionados com possíveis escoamentos superficiais. O intervalo de estudo selecionado compreendeu os meses de janeiro a dezembro de 1999, justamente quando se implantou, neste trabalho, um monitoramento mais efetivo neste sistema lacustre, com a instalação de uma estação climatológica (Estação Terra Nova) às margens da lagoa do Bonfim (Figura 1).

Tabela 1. Principais características das lagoas do sistema lacustre Bonfim (COSTA, 1996).

\begin{tabular}{cccc}
\hline Lagoas & $\begin{array}{c}\text { Área da } \\
\text { superfície } \\
\left(\mathrm{m}^{2}\right)\end{array}$ & $\begin{array}{c}\text { Volume } \\
\text { armazenado } \\
\left(\mathrm{m}^{3}\right)\end{array}$ & $\begin{array}{c}\text { Profundidade } \\
\text { máxima }(\mathrm{m})\end{array}$ \\
\hline Bonfim & 8.899 .936 & 84.268 .211 & 31,00 \\
Urubu & 899.870 & 2.736 .115 & 9,00 \\
Redonda & 993.211 & 3.720 .090 & 8,00 \\
Boa Água & 686.268 & 1.469 .132 & 4,00 \\
Ferreira Grande & 1.064 .065 & 2.812 .724 & 8,00 \\
Carcará & 665.125 & 1.570 .976 & 4,00 \\
\hline
\end{tabular}

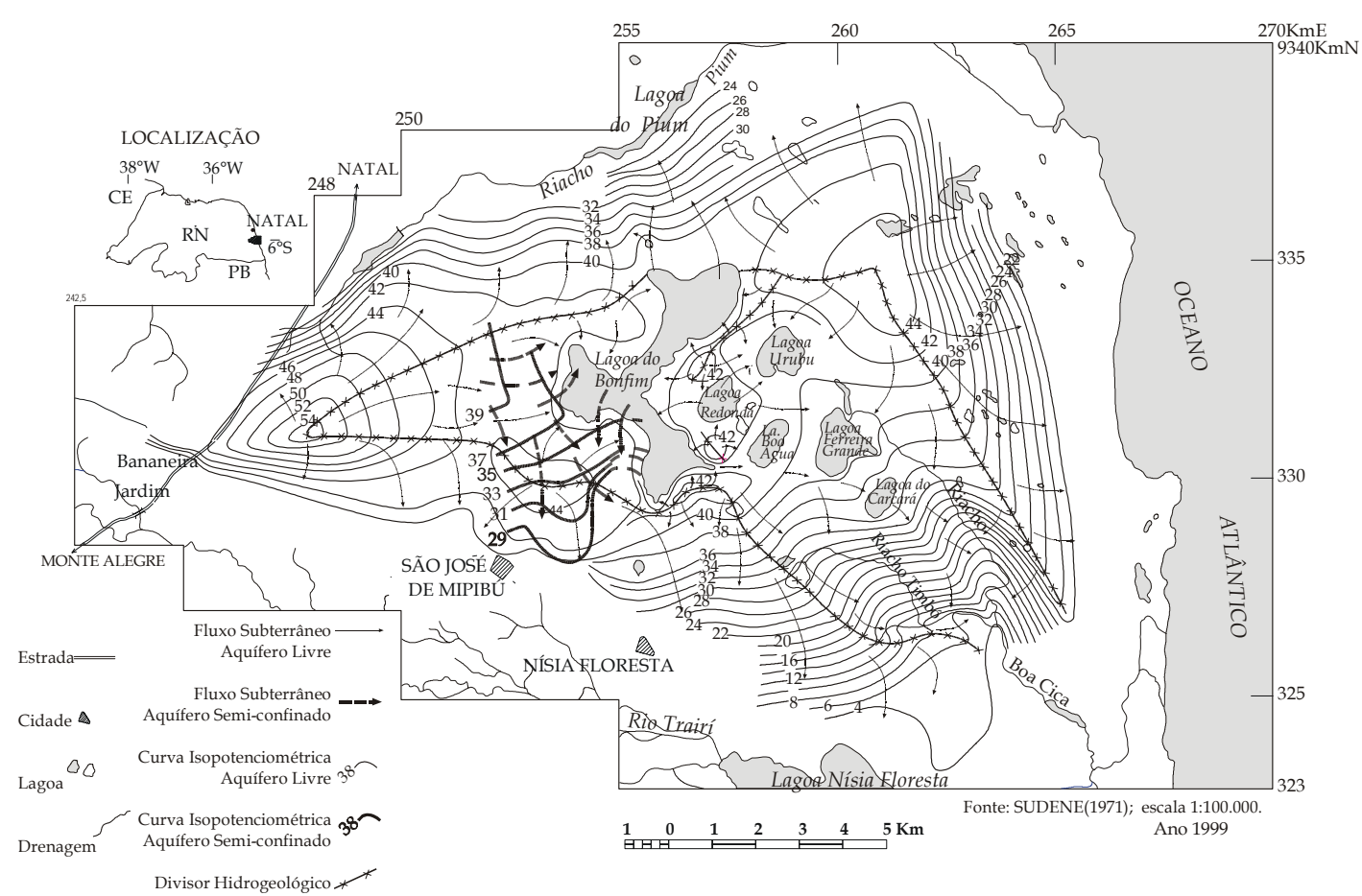

Figura 1 - Localização do sistema lacustre Bonfim, da estação hidrometeorológica Terra Nova e da captação da adutora Agreste Trairi Potengi. Além disso mostra o comportamento dos fluxos subterrâneos do aqüífero livre do sistema lacustre Bonfim. Secundariamente são apontados os fluxos do aqüífero semi-confinado no setor oeste da lagoa do Bonfim, sendo a sua recarga proveniente de oeste e da própria lagoa do Bonfim. 


\section{BALANÇO HÍDRICO DE LAGOS}

O balanço hídrico é um modelo conceitual de avaliação quantitativa dos recursos hídricos de uma região, relacionando os processos intervenientes no ciclo hidrológico. Analiticamente, o balanço hídrico é expresso pela equação (1) diferencial geral da continuidade (VILLELA \& MATTOS, 1975), baseada no princípio da conservação da massa de um sistema aplicado a um volume de controle, relacionando a taxa de variação do armazenamento interno com o saldo de fluxo externo no volume de controle.

$$
I-O=\frac{d s}{d t}
$$

Onde: I (input) e $O$ (output) são os totais de fluxos que entram e saem no volume de controle e ds/dt é a taxa de variação do armazenamento interno no volume de controle.

Na equação (2) geral do balanço hídrico de um lago fechado (UNESCO, 1981), a seguir, como é o caso da maioria das lagoas do sistema lacustre do Bonfim, exceto as lagoas do Urubu, transbordamento sazonal, e Ferreira Grande, transbordamento permanente, sendo que em condições excepcionais ocorrem nas demais, os fluxos de entrada (I) compreendem (Figura 2): o escoamento superficial $\left(\mathrm{Q}_{\mathrm{si}}\right)$, recarga da lagoa proveniente dos fluxos subterrâneos $\left(\mathrm{Q}_{\mathrm{ui}}\right)$ e as precipitações pluviais $(\mathrm{P})$ sobre a área do espelho d’água $(A)$. Os fluxos de saída $(\mathrm{O})$ são constituídos pela perda d'água por evaporação no espelho, determinada pelo produto da taxa de evaporação $(E)$ pela área do espelho d' água $(A)$; as perdas subterrâneas do lago $\left(\mathrm{Q}_{\mathrm{uo}}\right)$ e os consumo d'água $\left(\mathrm{Q}_{\text {cons. }}\right)$. A taxa de variação do armazenamento (ds/dt), em cada instante, pode ser avaliada pelo produto da área do espelho d’água $(A)$ pela taxa de variação do nível d’água do lago (dh/dt). Assim, a equação (2) pode ser expressa:

$$
I-O=A \cdot \frac{d h}{d t}
$$

Onde:

$$
\begin{array}{ll}
- & \mathbf{I}=\left(P . A+Q_{s i}+Q_{u i}\right)_{I}, \mathrm{e} \\
- & \mathbf{O}=\left(E . A+Q_{\text {uо }}+Q_{\alpha}+Q_{\text {cons. }}\right)_{O} .
\end{array}
$$

Para as condições das lagoas do sistema lacustre em foco, o escoamento superficial direto pode ser, inicialmente, desprezado, devido a não existência de uma rede de drenagem superficial direcionada para estas lagoas e o consumo d'água é expresso pela vazão bombeada pela adutora $\left(\mathrm{Q}_{\alpha}\right)$, apenas considerada para a lagoa do Bonfim, e outros usos relevantes $\left(\mathrm{Q}_{\beta}\right)$ de difícil caracterização, tais como a irrigação. Portanto, a equação (3) do balanço hídrico das lagoa do sistema lacustre Bonfim pode ser apresentada da seguinte forma:

$$
\left(P . A+Q_{u i}\right)_{I}-\left(E . A+Q_{u o}+Q_{\alpha}+Q_{\beta}\right)_{O}=A \cdot \frac{d h}{d t}
$$




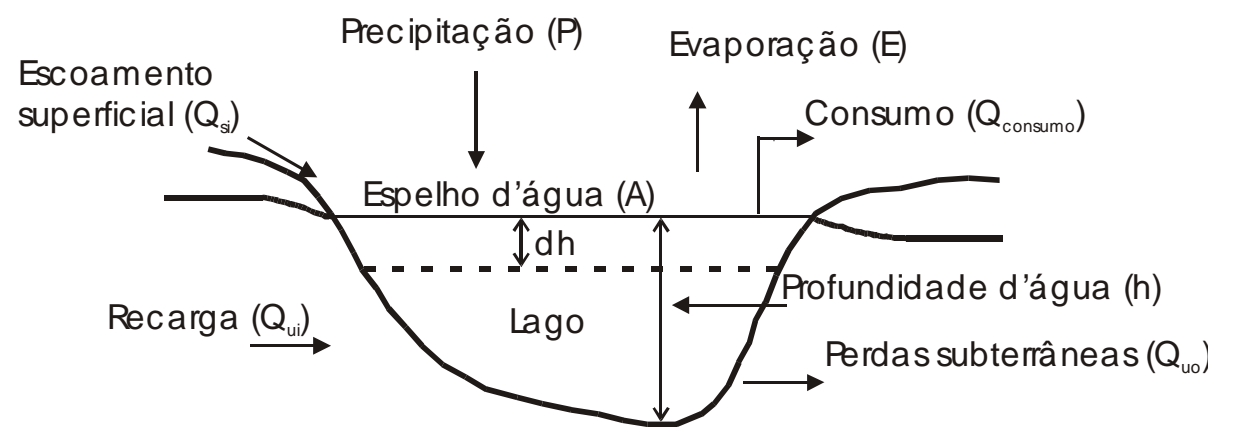

Figura 2 - Volume de controle e processos hidrológicos de um lago fechado.

\section{MODELO DO BALANÇO HÍDRICO}

Para avaliar as entradas e saídas de águas subterrâneas em cada lagoa do sistema lacustre Bonfim, o modelo aplicado teve como base a determinação mensal do saldo de fluxo do balanço hídrico, durante o período estudado, janeiro a dezembro de 1999, o qual deve ser entendido como um termo residual.

\section{Estimativa do saldo de fluxo}

Os componentes do saldo de fluxo do balanço hídrico, definidos no contexto do estudo, constituem as recargas e as perdas subterrâneas das lagoas e os outros consumos antrópicos de difícil caracterização, conforme anteriormente citado, os quais são apresentados na equação (4). Entretanto, para o caso específico da lagoa do Bonfim, o consumo resultante do bombeamento para a adutora foi fornecidos pela CAERN (Companhia Estadual de Águas e Esgotos do Rio Grande do Norte). É importante reconhecer que termos desconhecidos do balanço hídrico, come o caso das entradas e saídas subterâneas, obtidos a partir de uma ou mais variáveis medidas, acumulam os erros destas. Para isto, contou-se com informações mensais de variação do nível d'água das lagoas (apesar de existir informações diárias), e, principalmente, com os dados da estação hidrometeorológica Terra Nova, instalada às margens da lagoa do Bonfim, apresentando registros diários de precipitações pluviais, evaporação, velocidade e direção do vento, umidade relativa, temperatura do ar e pressão atmosférica.

$$
Q_{\text {saldo }}=Q_{u i}-\left(Q_{u o}+Q_{\beta}\right)
$$

Combinado-se as equações (3) e (4), tem-se:

$$
Q_{\text {saldo }}=A \cdot \frac{d h}{d t}-P \cdot A+\left(E \cdot A+Q_{\alpha}\right)
$$

Discretizando-se a equação diferencial (5) pelo método das diferenças finitas, segundo um esquema progressivo no tempo, para uma área da superfície do espelho d'água média $(\bar{A})$, no intervalo de tempo $(\Delta t)$ mensal, chega-se a seguinte expressão: 


$$
Q_{\text {saldo }}^{t}=\bar{A}\left(h^{t+1}-h^{t}-P^{t}+E^{t}\right)+Q_{\alpha}^{t}
$$

Onde: $Q_{\text {saldo }}^{t}$ e $Q_{\text {bomba }}^{t}$ são as vazões no mês atual $(t)$, em $\mathrm{m}^{3} / \mathrm{mês} ; h^{t}$ e $h^{t+1}$ são as profundidades d'água no inicio do mês atual e subseqüente, respectivamente, em m; $P^{t}$ e $E^{t}$ são, respectivamente, a precipitação pluvial e a evaporação no decorrer do mês atual, em $\mathrm{m} /$ mês. $\bar{A}$ é a área média mensal do espelho d'água, em $\mathrm{m}^{2}$, calculada a partir das áreas do espelho no início do mês atual e do mês subseqüente, conforme equação (7).

$$
\bar{A}=\frac{A^{t+1}+A^{t}}{2}
$$

Tanto a área do espelho (A) como o volume das lagoas são expressos como função da profundidade (h), mas neste trabalho se considerou esta como a altitude do nível do lagoa (m). As equações ou simplesmente interpolações obtidas para cada lagoa das relações cota-área e cota-volume, foram determinadas a partir dos dados do levantamento batimétrico realizado pela empresa COSTA (1997).

\section{RESULTADOS E DISCUSSÃO}

Os resultados da metodologia aplicada para as lagoas do sistema lacustre Bonfim, envolvendo todos os componentes do balanço hídricos, estão apresentados em tabelas a seguir (Tabela 2 a 6), sendo que a Tabela 7 apresenta uma síntese para cada lagoa, contendo informações do saldo de fluxo, disponibilidade hídrica subterrânea, escoamento superficial, características hidroquímicas e rebaixamentos, conforme será visto. Já a Figura 3 revela os domínios influentes e efluentes em cada lagoa do sistema lacustre Bonfim, conforme o mapa hidrogeológico (Figura 1). A Tabela 7 mostra, com base no saldo de fluxo total do período estudado, que a lagoa do Bonfim é a que apresenta a maior disponibilidade do período (36,4 L/s), depois a lagoa do Urubu com 17,6 L/s. Apesar disso, a fragilidade da lagoa do Bonfim, frente à explotação do sistema adutor no período analisado, pode ser constatada considerando que o volume positivo resultante do somatório do saldo de fluxo, em torno de $\mathbf{+ 1 . 0 5 2 . 8 0 8} \mathrm{m}^{3}$, o qual corresponde apenas ao fluxo subterrâneo de entrada que fica disponível no lago (armazenado), é bastante pequeno em relação ao volume bombeado pela adutora que foi de $\mathbf{5 . 6 6 8 . 9 5 5} \mathrm{m}^{3}$, correspondendo a 195,8 L/s, (5,4 vezes a mais que a sua disponibilidade do período) daí o maior rebaixamento acentuado na lagoa do Bonfim (mascarando o comportamento natural), conforme descrito em Pereira (2001), faltando apenas $22 \mathrm{~cm}$ para atingir a cota absoluta limite de $39 \mathrm{~m}$ do espelho dessa lagoa, no início de 2000. Esse processo também está relacionado com a ausência de infiltração eficaz das chuvas deste ano de 1999, em sua zona de recarga principal, setor oeste (Figura 4), uma vez que a curva de rebaixamento dos níveis d' água dos piezômetros mantiveram a mesma tendência de descida até a recarga das chuvas do ano seguinte (2000).

Ainda observando o comportamento das precipitações com o saldo de fluxo (Figura 5), no período de novembro de 1998 a março de 2000, nota-se uma tendência de correlação entre ambas. Com base nisto e considerando que a principal área de contribuição subterrânea da lagoa do Bonfim não teve recarga neste período, conforme explicado anteriormente, os valores positivos elevados deste saldo nos meses de abril a junho de 1999, podem ser um fator indicativo da possibilidade de existência de fluxos 
superficiais (ou até mesmo hipodérmico), não contabilizados no balanço, os quais devem ocorrer nas proximidades desta lagoa. Este aumento do saldo de fluxo deve ter tido pouco influência da redução da irrigação na lagoa do Bonfim, pois a atividade já havia sido diminuída nesta (por solicitação do governo Estadual, dado o seu rebaixamento acentuado), quando as chuvas se iniciaram de forma expressiva em abril de 1999. Assim, uma das possibilidades para explicar os valores positivos acentuados do saldo de fluxo da lagoa do Bonfim seria os prováveis escoamentos superficiais, normalmente não considerados, devido às características pedológicas da área, mas que no caso da lagoa do Bonfim poderia ocorrer fluxos secundários, em função da impermeabilização do seu entorno e do solo que, neste caso, é mais areno-argiloso, resultante das rochas da Formação Barreiras.

No caso das outras lagoas, onde o solo das dunas é essencialmente arenoso, o escoamento superficial foi totalmente desconsiderado, mesmo porque a recuperação piezométrica da zona de recarga deste setor ocorreu quase que imediatamente (da ordem de dias) à recuperação das lagoas (Figura 4), no mês de abril, a qual se propagou até junho, o que não se verificou com a lago do Bonfim. Neste caso, diferente da lagoa do Bonfim, os saldos positivos nos meses de abril a junho de 1999, representam efetivamente aumento da recarga subterrânea.

Entre as pequenas lagoas, as que tiveram os menores rebaixamento totais e maiores recuperações (durante as precipitações do período chuvoso de 1999) foram as lagoas do Urubu e Boa Água, coincidindo justamente com um saldo de fluxo positivo, sendo as que mais sofreram rebaixamentos e menores recuperações foram justamente as lagoas redondas e carcará, com saldo de fluxo negativo.

Para explicar o comportamento do saldo de fluxo dessas lagoas menores, toma-se como exemplo duas situações opostas sobre a interação das águas superficiais e subterrâneas, como são os casos das lagoas Redonda (menor saldo) e Urubu (maior saldo). Pode-se observar na Figura 3 que a face ou margem da lagoa do Urubu que atua como influente, ou seja, repassa água subterrânea para o aqüífero livre é muito menor que a face que a alimenta (condição de efluência). A lagoa Redonda, por sua vez, tem comportamento totalmente contrário, mais perdendo do que recebendo. Enquanto o comportamento da lagoa Boa água se aproxima da lagoa do Urubu, a lagoa do carcará assemelha-se ao da Redonda. 
PEREIRA, R.

Tabela 2 - Saldo de fluxo do balanço hídrico da lagoa do Bonfim.

\begin{tabular}{|c|c|c|c|c|c|c|c|c|c|}
\hline \multirow[t]{2}{*}{ Data } & $\begin{array}{l}\text { Nível } \\
\text { do }\end{array}$ & Volume & Área & \multicolumn{2}{|c|}{ Evaporação } & \multirow{2}{*}{$\begin{array}{l}\text { Precip. } \\
(\mathrm{mm}) \\
\end{array}$} & \multirow{2}{*}{$\begin{array}{l}\text { Adutora } \\
\left(\mathrm{m}^{3}\right) \\
\end{array}$} & \multirow{2}{*}{$\begin{array}{l}\text { Saldo de } \\
\text { Fluxo }\left(\mathrm{m}^{3}\right) \\
\end{array}$} & \multirow{2}{*}{$\begin{array}{c}\text { Irrigação } \\
\left(\mathrm{m}^{3}\right)\end{array}$} \\
\hline & $\begin{array}{l}\text { Lago } \\
(\mathrm{m})\end{array}$ & $\left(\mathrm{m}^{3}\right)$ & $\left(\mathrm{m}^{2}\right)$ & $\begin{array}{c}\text { Tanque }\left(\mathrm{Ev}_{\mathrm{t}}\right) \\
(\mathrm{mm})\end{array}$ & $\begin{array}{c}\text { Real } \\
\mathrm{Ev}_{\mathrm{t}} \times 0,75 \\
(\mathrm{~mm})\end{array}$ & & & & \\
\hline $1 / 01 / 99$ & 41,302 & 70.664 .767 & 7.852 .447 & 214,5 & 160,9 & 5,7 & 372.948 & -283.075 & 173.934 \\
\hline 1/02/99 & 41,065 & 68.803 .081 & 7.686.953 & 199,1 & 149,3 & 97,4 & 431.938 & -91.191 & 161.142 \\
\hline 1/03/99 & 40,946 & 67.882.939 & 7.604 .825 & 207,1 & 155,3 & 42,7 & 326.238 & -30.105 & 44.970 \\
\hline 1/04/99 & 40,788 & 66.676.187 & 7.496.772 & 201,2 & 150,9 & 138,6 & 693.616 & 422.371 & 44.610 \\
\hline 1/05/99 & 40,740 & 66.312.932 & 7.464.169 & 149,3 & 112,0 & 234,9 & 568.949 & 254.363 & 35.370 \\
\hline 1/06/99 & 40,820 & 66.919.222 & 7.518 .565 & 160,6 & 120,5 & 102,3 & 539.736 & 175.290 & 35.010 \\
\hline 1/07/99 & 40,754 & 66.418 .721 & 7.473.667 & 189,8 & 142,4 & 43,5 & 666.130 & 63.754 & 26.370 \\
\hline 1/08/99 & 40,576 & 65.083 .510 & 7.353.555 & 210,2 & 157,7 & 32,1 & 628.987 & 164.452 & 24.690 \\
\hline 1/09/99 & 40,389 & 63.703 .562 & 7.228.894 & 215,7 & 161,8 & 28,8 & 436.333 & 133.922 & 33.930 \\
\hline 1/10/99 & 40,216 & 62.447 .465 & 7.114.946 & 235,3 & 176,5 & 17,4 & 504.080 & -1.561 & 34.290 \\
\hline $1 / 11 / 99$ & 39,988 & 60.821 .799 & 6.966.781 & 234,7 & 176,0 & 8,4 & 500.000 & 244.588 & 33.930 \\
\hline 1/12/99 & 39,786 & 59.409 .424 & 6.837 .404 & - & - & - & Total = & +1.052 .808 & - \\
\hline
\end{tabular}

Tabela 3 - Saldo de fluxo do balanço hídrico da lagoa Redonda.

\begin{tabular}{|c|c|c|c|c|c|c|c|}
\hline Período & $\begin{array}{c}\text { Nível do lago } \\
\text { (m) }\end{array}$ & $\begin{array}{c}\text { Volume } \\
\left(\mathrm{m}^{3}\right)\end{array}$ & $\begin{array}{l}\text { Área } \\
\left(\mathrm{m}^{2}\right) \\
\end{array}$ & $\begin{array}{c}\text { Evaporação } \\
\text { Tanque (mm) }\end{array}$ & $\begin{array}{l}\text { Evaporação Real = } \\
E_{\mathrm{t}} \times 0,75(\mathrm{~mm})\end{array}$ & $\begin{array}{c}\text { Precipitação } \\
(\mathrm{mm})\end{array}$ & $\begin{array}{c}\text { Saldo de } \\
\text { Fluxo }\left(\mathrm{m}^{3}\right)\end{array}$ \\
\hline 1/01/99 & 41,738 & 2.384 .420 & 720.883 & 214,5 & 160,9 & 5,7 & -63.816 \\
\hline 1/02/99 & 41,505 & 2.211 .557 & 684.591 & 199,1 & 149,3 & 97,4 & -39.997 \\
\hline 1/03/99 & 41,398 & 2.136 .429 & 668.542 & 207,1 & 155,3 & 42,7 & -33.624 \\
\hline 1/04/99 & 41,238 & 2.028 .823 & 645.243 & 202,5 & 151,9 & 138,6 & 11.850 \\
\hline 1/05/99 & 41,243 & 2.032 .102 & 645.959 & 149,3 & 112,0 & 234,9 & 75.233 \\
\hline 1/06/99 & 41,473 & 2.188 .816 & 679.751 & 160,6 & 120,5 & 102,3 & 63.211 \\
\hline 1/07/99 & 41,544 & 2.239 .592 & 690.535 & 189,8 & 142,4 & 43,5 & 13.381 \\
\hline 1/08/99 & 41,468 & 2.185 .284 & 678.998 & 210,2 & 157,7 & 32,1 & -18.135 \\
\hline 1/09/99 & 41,320 & 2.083.276 & 657.080 & 215,7 & 161,8 & 28,8 & -40.359 \\
\hline 1/10/99 & 41,127 & 1.957.372 & 629.558 & 235,3 & 176,5 & 17,4 & -23.266 \\
\hline 1/11/99 & 40,929 & 1.836.109 & 602.521 & 234,7 & 176,0 & 8,4 & -31.289 \\
\hline 1/12/99 & 40,702 & 1.706.301 & 572.949 & - & - & Total $=$ & -86.812 \\
\hline
\end{tabular}




\section{Tabela 4 - Saldo de fluxo do balanço hídrico da lagoa do Urubu.}

\begin{tabular}{cccccccc}
\hline Período & Nível d’água & Volume & Área & $\begin{array}{c}\text { Evaporação } \\
\text { Tanque } \\
(\mathrm{mm})\end{array}$ & $\begin{array}{c}\text { Evaporação } \\
\text { Real }= \\
\text { Ev }_{\mathrm{t}} \mathrm{0,75} \\
(\mathrm{mm})\end{array}$ & $\begin{array}{c}\text { Precipitação } \\
(\mathrm{mm})\end{array}$ & Saldo de \\
\hline Fluxo $\left(\mathrm{m}^{3}\right)$
\end{tabular}

Tabela 5 - Saldo de fluxo do balanço hídrico da lagoa Boa Água.

\begin{tabular}{cccccccc}
\hline \multicolumn{2}{c}{ Período Nível d’água } & Volume & Área & \multicolumn{2}{c}{ Evaporação } & \multicolumn{3}{c}{ Evaporação Real = Precipitação } & Saldo de \\
& $(\mathrm{m})$ & $\left(\mathrm{m}^{3}\right)$ & $\left(\mathrm{m}^{2}\right)$ & Tanque $(\mathrm{mm})$ & $\mathrm{Ev}_{\mathrm{t}} \times 0,75(\mathrm{~mm})$ & $(\mathrm{mm})$ & ${\text { Fluxo }\left(\mathrm{m}^{3}\right)}$ \\
\hline $1 / 01 / 99$ & 41,058 & 645.018 & 445.252 & 214,5 & 160,9 & 5,7 & -33.778 \\
$1 / 02 / 99$ & 40,844 & 545.052 & 407.824 & 199,1 & 149,3 & 97,4 & -24.883 \\
$1 / 03 / 99$ & 40,733 & 499.464 & 389.667 & 207,1 & 155,3 & 42,7 & -14.103 \\
$1 / 04 / 99$ & 40,580 & 442.810 & 365.957 & 202,5 & 151,9 & 138,6 & 18.697 \\
$1 / 05 / 99$ & 40,619 & 456.610 & 371.860 & 149,3 & 112,0 & 234,9 & 53.231 \\
$1 / 06 / 99$ & 40,874 & 558.073 & 412.875 & 160,6 & 120,5 & 102,3 & 50.012 \\
$1 / 07 / 99$ & 40,967 & 600.445 & 428.934 & 189,8 & 142,4 & 43,5 & 4.178 \\
$1 / 08 / 99$ & 40,885 & 562.924 & 414.743 & 210,2 & 157,7 & 32,1 & -7.697 \\
$1 / 09 / 99$ & 40,746 & 504.600 & 391.751 & 215,7 & 161,8 & 28,8 & -14.982 \\
$1 / 10 / 99$ & 40,570 & 439.339 & 364.459 & 235,3 & 176,5 & 17,4 & -13.458 \\
$1 / 11 / 99$ & 40,353 & 370.374 & 333.412 & 234,7 & 176,0 & 8,4 & -8.958 \\
$1 / 12 / 99$ & 40,119 & 308.086 & 302.890 & - & - & Total = & $+\mathbf{8 . 2 5 8}$ \\
\hline
\end{tabular}


Tabela 6 - Saldo de fluxo do balanço hídrico da lagoa do Carcará.

\begin{tabular}{cccccccc}
\hline Período & $\begin{array}{c}\text { Nível d’água } \\
(\mathrm{m})\end{array}$ & $\begin{array}{c}\text { Volume } \\
\left(\mathrm{m}^{3}\right)\end{array}$ & $\begin{array}{c}\text { Área } \\
\left(\mathrm{m}^{2}\right)\end{array}$ & $\begin{array}{c}\text { Evaporação } \\
\text { Tanque }(\mathrm{mm})\end{array}$ & $\begin{array}{c}\text { Evaporação Real = } \\
\mathrm{Ev}_{\mathrm{t}} \times 0,75(\mathrm{~mm})\end{array}$ & $\begin{array}{c}\text { Precipitação } \\
(\mathrm{mm})\end{array}$ & $\begin{array}{c}\text { Saldo de } \\
\text { Fluxo }\left(\mathrm{m}^{3}\right)\end{array}$ \\
\hline $1 / 01 / 99$ & 34,512 & 523.715 & 382.168 & 214,5 & 160,9 & 5,7 & -13.045 \\
$1 / 02 / 99$ & 34,297 & 453.301 & 357.245 & 199,1 & 149,3 & 97,4 & -20.121 \\
$1 / 03 / 99$ & 34,180 & 414.982 & 343.682 & 207,1 & 155,3 & 42,7 & -19.081 \\
$1 / 04 / 99$ & 34,007 & 358.323 & 323.628 & 202,5 & 151,9 & 138,6 & 2.655 \\
$1 / 05 / 99$ & 34,002 & 356.686 & 323.048 & 149,3 & 112,0 & 234,9 & 21.162 \\
$1 / 06 / 99$ & 34,192 & 418.912 & 345.073 & 160,6 & 120,5 & 102,3 & 21.048 \\
$1 / 07 / 99$ & 34,237 & 433.650 & 350.290 & 189,8 & 142,4 & 43,5 & 9.300 \\
$1 / 08 / 99$ & 34,161 & 408.759 & 341.480 & 210,2 & 157,7 & 32,1 & 1.360 \\
$1 / 09 / 99$ & 34,037 & 368.149 & 327.106 & 215,7 & 161,8 & 28,8 & -14.495 \\
$1 / 10 / 99$ & 33,864 & 311.490 & 307.051 & 235,3 & 176,5 & 17,4 & -25.909 \\
$1 / 11 / 99$ & 33,642 & 238.783 & 281.317 & 234,7 & 176,0 & 8,4 & -17.254 \\
$1 / 12 / 99$ & 33,451 & 176.229 & 259.176 & - & - & Total = & -54.381 \\
\hline
\end{tabular}

Tabela 7 - Síntese das características hidrológicas e hidroquímicas das lagoas do sistema lacustre Bonfim.

\begin{tabular}{cccccc}
\hline Lagoas & $\begin{array}{c}\text { Saldo de } \\
\text { Fluxo } \\
\text { Total }\left(\mathrm{m}^{3}\right)\end{array}$ & $\begin{array}{c}\text { Disponibilidade } \\
(\mathrm{L} / \mathrm{s})\end{array}$ & $\begin{array}{c}\text { Classificação } \\
\text { Hidroquímica }\end{array}$ & $\begin{array}{c}\text { Escoamento } \\
\text { Superficial }\end{array}$ & $\begin{array}{c}\text { Rebaixamento } \\
\text { do Período }(\mathrm{m})\end{array}$ \\
\hline Bonfim & $\mathbf{+ 1 . 0 5 2 . 8 0 8}$ & 36,4 & Cloretada-Sódica & Presente & 1,51 \\
Redonda & $\mathbf{- 8 6 . 8 1 2}$ & - & Cloretada-Sódica & Ausente & 1,04 \\
Urubu & $\mathbf{+ 5 0 9 . 8 1 5}$ & 17,6 & Cloretada-Cálcica & Ausente & 0,26 \\
Boa Água & $\mathbf{+ 8 . 2 5 8}$ & $0,3 \mathrm{~L} / \mathrm{s}$ & Cloretada-Cálcica & Ausente & 0,94 \\
Carcará & $\mathbf{- 5 4 . 3 8 1}$ & - & Cloretada Sódica & Ausente & 1,06 \\
\hline
\end{tabular}

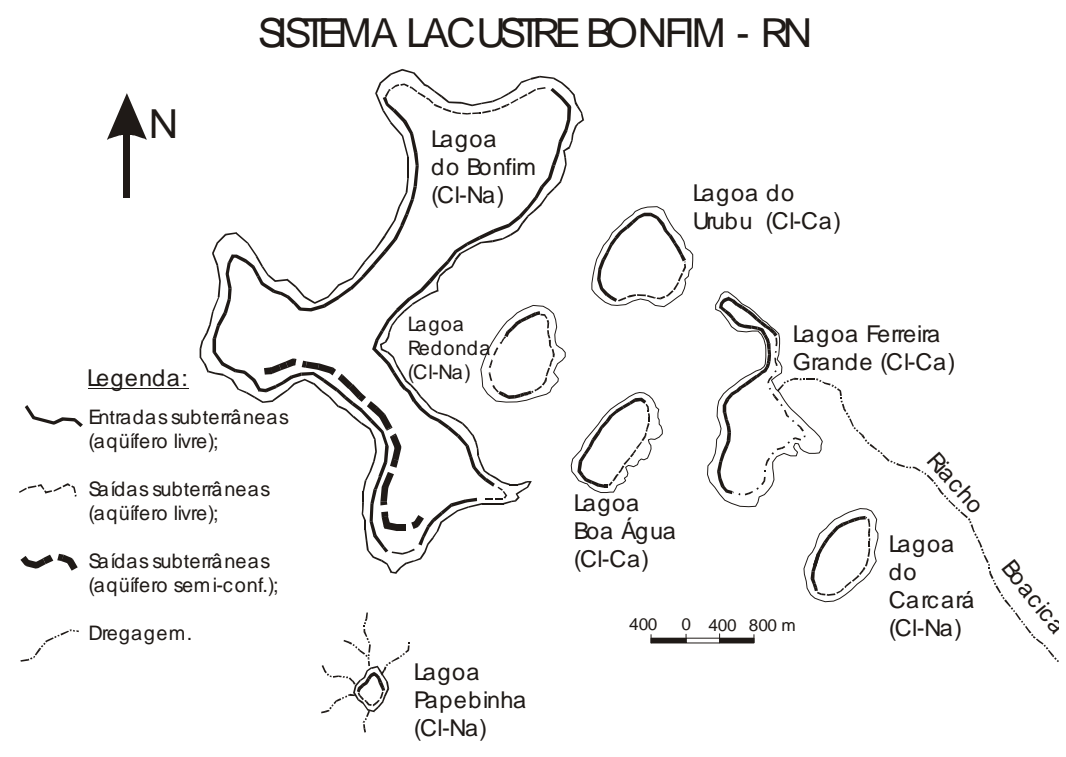

Figura 3 -Entradas (condição de efluência) de águas subterrâneas e saídas (condição de influência) para o aqüífero livre nas margens das lagoas do sistema lacustre Bonfim - RN. Apenas a lagoa do Bonfim mostra condição de perdas subterrâneas para o aqǘf́ero semi-confinado no setor oeste. 


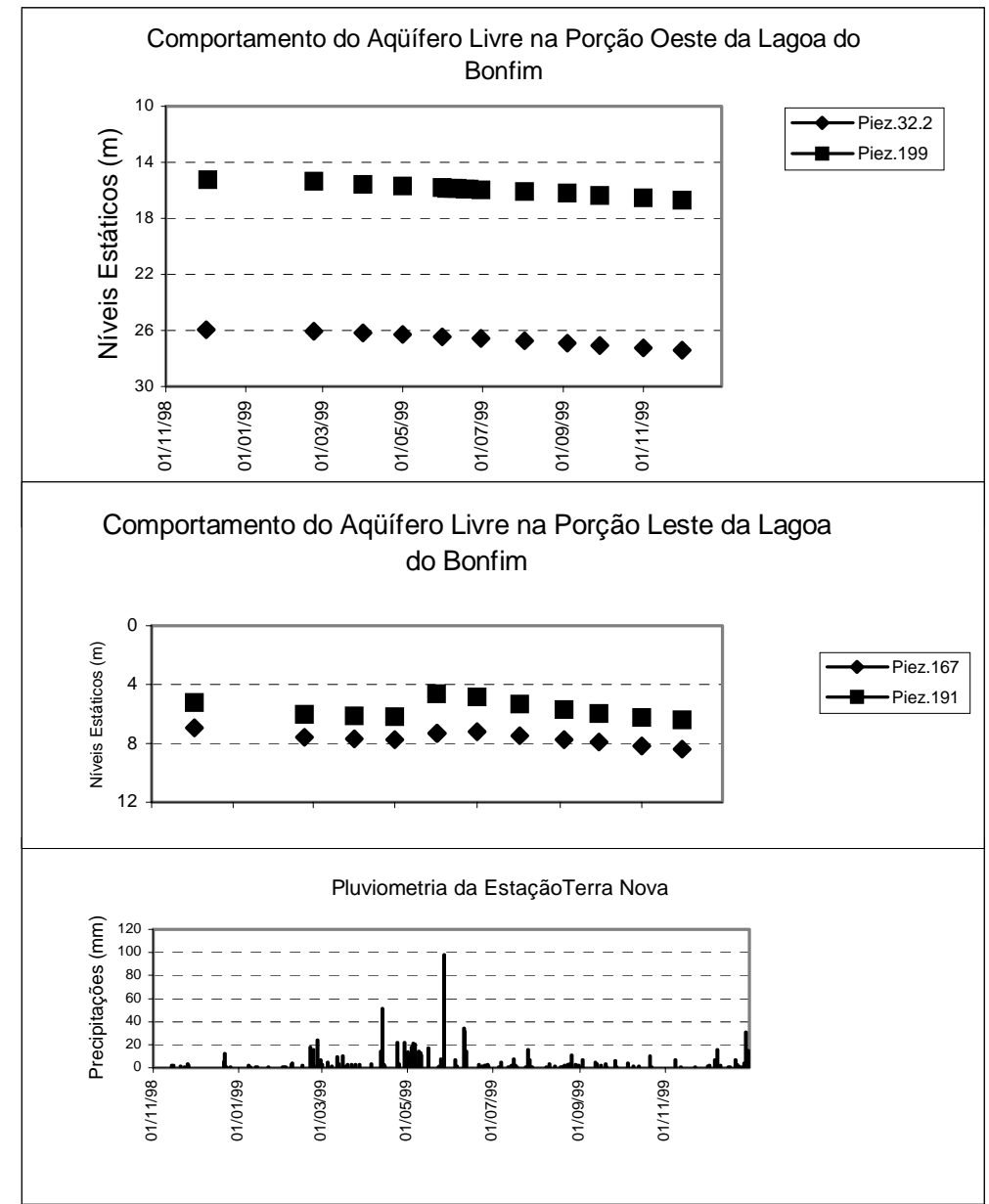

Figura 4 - Curvas de variações do aqüífero livre nos setores leste e oeste da lagoa do Bonfim em piezômetros com diferentes profundidades dos níveis estáticos. No caso do setor oeste da lagoa do Bonfim os piezômetros mostraram rebaixamentos contínuos com as precipitações de 1999, indicando ausência de recarga. Por outro lado os níveis d' água do setor leste, onde ocorrem as dunas, evidenciaram recuperação.

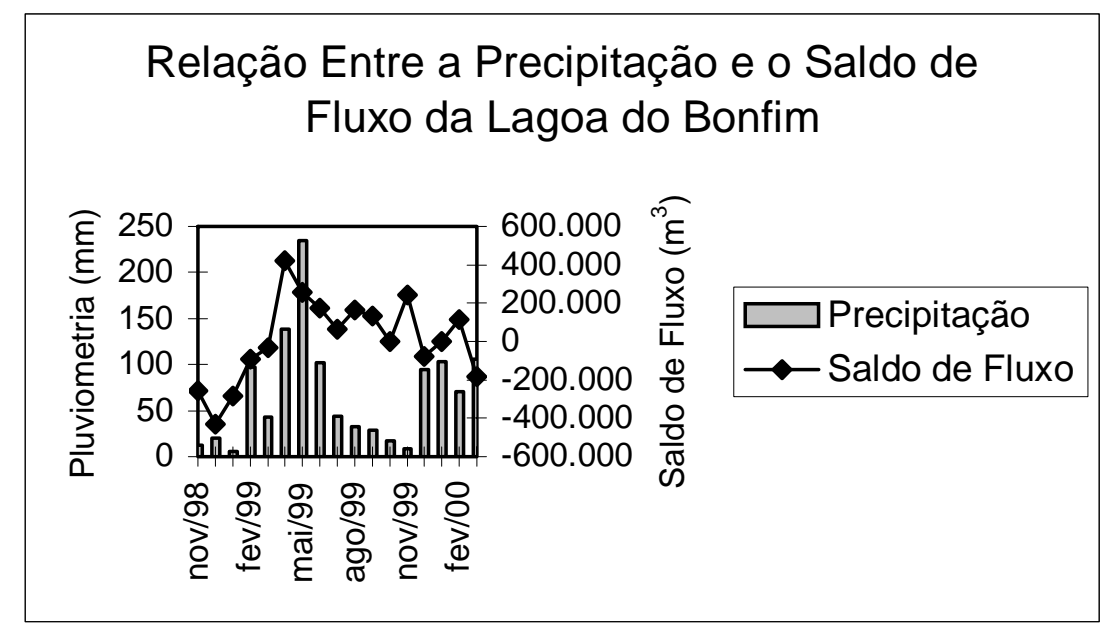

Figura 5 - Comportamento das precipitações com o saldo de fluxo da lagoa do Bonfim, no período de novembro de 1998 a março de 2000. 


\section{Classificação Hídroquímica das Lagoas}

A classificação hidroquímica das lagoas e do aqüífero livre se procedeu mediante aplicação dos resultados das análises físico-químicas (efetuadas em Outubro/1999) no diagrama de Piper (PEREIRA, 2001). Os dados plotados no referido diagrama revelaram que as águas do aqüífero livre, nas imediações das lagoas estudadas, são cloretadas cálcicas. Entretanto, as lagoas se classificaram hidroquimicamente em dois grupos. O primeiro, com águas cloretadas sódicas, é composto pelas lagoas do Bonfim, Redonda e Carcará. Já o segundo, de caráter cloretado cálcico, pelas lagoas do Urubu e Boa Água. Com exceção da lagoa do Bonfim, pode-se perceber que quando a condição de efluência domina, ou seja, o saldo de fluxo é positivo, as lagoas são cloretadas cálcicas, predominando as características iônicas das águas do aqüífero no seu balanço químico. Apesar de não ter sido determinado o saldo de fluxo da lagoa Ferreira Grande, em função da ausência de alguns períodos de dados de níveis d’águas, assim como as vazões de saída, a sua condição de efluência sintetizada na figura 4, a partir do mapa hidrogeológico, recebendo águas cloretadas cálcicas das lagoas Boa Água e Urubu parece dominar e, portanto, também as suas características cloretadas cálcicas. Caso contrário, quando o saldo é negativo, quer dizer, as lagoas predominantemente influem no aqüífero (Redonda e Carcará) são cloretadas sódicas. Neste caso, poder-se-ia ter uma maior influência dos aerossóis marinhos e a conseqüente concentração de cloreto de sódio por evaporação, no seu balanço químico. Esta informação é particularmente importante para a lagoa Redonda, apresentando, dentre as supracitadas, a maior concentração de sais totais dissolvidos (136 $\mathrm{mg} / \mathrm{L})$.

No caso específico da lagoa do Bonfim, os dados foram contraditórios, pois enquanto o saldo de fluxo foi positivo, a água é cloretada sódica, diferente das águas do aqüífero que a circunda que são cloretadas cálcicas. Todavia, pela relação estudada entre o saldo de fluxo e as precipitações (Figura 5), constatou-se, conforme foi aventado, que o papel do escoamento sobre o terreno em direção à esta lagoa, não contabilizado no balanço, pode ter tido alguma influência expressiva nos valores positivos do saldo (Tabela 2), mascarando a interpretação deste termo residual.

Entretanto, fazendo abstração desse saldo positivo nos meses de abril a junho de 1999, quando ocorreram as maiores precipitações, o saldo total fica em torno de +200.000 $\mathrm{m}^{3}$. Adicionalmente, desconsiderando o saldo positivo significativamente elevado do mês de novembro de 1999, o qual deve representar algum erro, já que não houve recarga neste período de 1999 na bacia desta lagoa, o saldo total ficaria negativo ou próximo de zero. Justifica-se, assim, a sua classificação como cloretada sódica à semelhança do comportamento das pequenas lagoas. Dados regionais, entretanto, indicam que as águas do Barreiras são predominantemente cloretadas sódicas, o que precisa ser comprovado através de um monitoramento no entorno da lagoa do Bonfim

Portanto, este saldo de fluxo negativo ou próximo de zero estimado para a lagoa do Bonfim, quando se faz a abstração das possíveis contribuições dos escoamentos superficiais, só não deve vigorar em condições de precipitações excepcionais quando deverá ocorrer recarga subterrânea também significativa, pois as evidências mostraram que em condições de precipitações médias ou ligeiramente acima da média, como foi o ano de 1997 (com 1381,5 mm) (Melo \& Feitosa, 1998), a recarga foi ausente ou mínima, já que o comportamento piezométrico do sistema lacustre Bonfim foi semelhante ao ano de 1999 (com 845,8 mm anuais). Isto quer dizer que as precipitações sobre o espelho, somadas com 
o escoamento superficial, deve ter um papel importante como regulador hidrológico na recuperação desta lagoa em condições hidrológicas médias.

Adicionalmente, apesar de parecer dominar a condição de efluência lateral do aqüífero livre na lagoa do Bonfim (Figura 3), Pereira (2001) também mostrou através de balanço hídrico, comparação de bacias vizinhas e a utilização da equação de Darcy que, na ausência de recargas excepcionais, as perdas subterrâneas, comentadas adiante, são iguais ou maiores que a recarga, corroborando o saldo negativo ou próximo de zero aqui estimado, quando se desconsidera o escoamento superficial do terreno em direção à lagoa do Bonfim. Estes aspectos reforçam a fragilidade em relação a sua disponibilidade hídrica. Pereira (2001) aponta perdas subterrâneas rasas e profundas desta lagoa em direção ao riacho Timbó (através da análise da vazão específica deste e comparação de características hidroquímicas entre os mesmos) e rio Trairi, sendo este principalmente através do aqüífero semi-confinado à SE-SW desta lagoa, quando se constatou a relação existente entre o comportamento da lagoa do Bonfim e este aqüífero. Além disso, as perdas para o rio Pium, a norte, são bastante expressivas, devido, provavelmente, à existência das descontinuidades estruturais neste setor.

Por fim, a característica hidroquímica cloretada sódica dominante na lagoa do Bonfim deve ser devido à concentração dos aerossóis marinhos de cloreto de sódio pela evaporação sobre a superfície do seu espelho d’água (da mesma maneira que algumas lagoas menores), provavelmente também acrescida do retorno dos depósitos de sais de evaporação, particularmente dos cloretos de sódio. Esta última hipótese de lixiviação do solo pode também ser evidenciada a partir do trabalho de Duarte (1999), o qual constatou, durante o seu monitoramento no ano de 1997, que ocorre um aumento da concentração de sódio, cloro e coliforme fecais com a chegada do período chuvoso nesta lagoa. Este processo de salinização das lagoas, pela lixiviação solo, está também claro quando associado com o retorno das irrigações, como é o caso da lagoa Papebinha, a SE da lagoa do Bonfim, conforme verificado em campo (ver a sua drenagem significativa na figura 3), porquanto embora a classificação desta como cloretada sódica esteja coerente com a sua condição equilibrada de influência - efluência, a mesma está caracterizada por um elevado conteúdo de sais totais dissolvidos (181 mg/L), sendo o maior de todas.

\section{CONCLUSÕES}

Uma relação positiva entre o saldo de fluxo e a classificação hidroquímica demonstrou existir quando não ocorre significativo escoamento superficial. O saldo de fluxo mostrou ser um bom indicador de escoamento superficial quando se monitora também as variações piezométricas na zona de recarga das respectivas lagoas. Por outro lado, quando não ocorre escoamento superficial também revela ser um bom indicador de análise do aumento de recarga subterrânea. O saldo de fluxo aqui considerado também mostrou ser uma ferramenta importante no estudo e controle da disponibilidade hídrica das lagoas, bem como na avaliação dos impactos ambientais frente a uma superexplotação das mesmas. O escoamento superficial parece ter um papel importante no armazenamento da lagoa do Bonfim. Por fim, é preciso analisar o comportamento hidroquímico da lagoa do Bonfim e o seu respectivo saldo de fluxo em condições de recargas subterrâneas excepcionais para avaliar as relações aqui discutidas, bem como o efeito de retardo da infiltração eficaz no saldo de fluxo. 


\section{AGRADECIMENTOS}

O autor agradecem ao Centro Federal de Educação Tecnológica do Rio Grande do Norte (CEFET), a Universidade Federal do Rio Grande do Norte (UFRN), na pessoa do Professor João Abner, e a Universidade Federal do Rio de Janeiro (UFRJ), na pessoa do Professor Gerson Cardoso da Silva Junior.

\section{REFERÊNCIAS}

COSTA - Consultoria e Serviços Técnicos e Ambientais Ltda/SERHID (1997). Estudos da Disponibilidade Hídrica da Lagoa do Bonfim.

DUARTE, M.A.C. (1999). Utilização dos Índices do Estado Trófico (IET) e de qualidade da água (IQA) na caracterização limnológica e sanitária das Lagoas de Bonfim, Extremóz e Jiqui - RN. Dissertação de Mestrado, Universidade Federal da Paraíba. $144 \mathrm{p}$.

MELO, J.G.; FEITOSA, E.C. (1998). Pesquisa Hidrogeológica do Complexo Lagunar do Bonfim. Convênio UFRN/SEHID.

PEREIRA, R.; CHIAVENATO, M. C.; FREITAS, J.; REIS, L. M. M. (1996). Carta Geotécnica do Município de Nísia Floresta - Rn. In: SIMPÓSIO BRASILEIRO DE CARTOGRAFIA GEOTÉCNICA, 2, São Carlos, 1996. Boletim...,ABGE, p.233239.

PEREIRA, R. (2001). Caracterização Hidrológica do Sistema Lacustre Bonfim - RN, Brasil. Tese de doutorado, Universidade Federal do Rio de Janeiro. 212 p.

SUDENE (1990). Dados Pluviométricos Mensais do Nordeste. Recife (Série Pluviométrica , 4)..

UNESCO (1981). Methods of Computation of the Water Balance of Large Lakes and Reservoirs. Fontenoy, Paris. 122 p.

VILLELA, S.M.; MATTOS, A. (1975). Hidrologia Aplicada. São Paulo, McGraw-Hill do Brasil. 245 p. 